
\title{
$\begin{array}{ll}\text { Research Square } & \begin{array}{l}\text { Preprints are preliminary reports that have not undergone peer review. } \\ \text { They should not be considered conclusive, used to inform clinical practice, } \\ \text { or referenced by the media as validated information. }\end{array}\end{array}$ \\ Optimization Parameter for Micro-Gripper Based on Triple-Stair Compliant Mechanism Using GTs- TOPSIS
}

\section{Chia-Nan Wang}

National Kaohsiung University of Science and Technology

Thi Diem-My Le ( $\square$ Itdiemmy160695@gmail.com )

National Kaohsiung University of Science and Technology

\section{Research Article}

Keywords: Microgripper mechanism, Triple-stair half bridge-type, Grey relational analysis, Entropy weight, TO PSIS method.

Posted Date: December 17th, 2021

DOI: https://doi.org/10.21203/rs.3.rs-1146201/v1

License: (c) (i) This work is licensed under a Creative Commons Attribution 4.0 International License.

Read Full License 


\title{
Optimization parameter for micro-gripper based on triple-stair compliant Mechanism using GTs-TOPSIS
}

\author{
Chia-Nan Wang ${ }^{1}$. Thi Diem-My Le ${ }^{1 *}$ \\ *Correspondence: Itdiemmy160695@gmail.com.
}

\begin{abstract}
In manipulating the assembly of micro-components, the symmetrical microgripper mechanism often causes destruction, damaging the micro-components during manipulation. The reason is due to the phenomenon of non-uniform clamping force output of the clamp. From this disadvantage, a new asymmetric microgripper structure is proposed with stable output clamping force. The asymmetric microgripper structure will have a smaller output displacement than the symmetric structure. Therefore, to increase the output displacement gain, a flexible hinge with a triple stair half bridge-style mechanism is adopted to design the amplifier of the asymmetrical microgripper. The finite element method is applied to analyze the displacement and stress. The optimization process is performed based on the geometric parametric properties of the structure. Using the technology for order preference by similarity to ideal solution (TOPSIS) based on the grey relationship analysis (GRA) obtained the maximal displacement output and minimal stress. The results show that the maximum output displacement is $5,818 \mathrm{~mm}$, stress after analysis is $2,432 \mathrm{MPa}$. The test is conducted to verify the optimal results and the effectiveness of the optimization method. Finally, experimental experiments were performed, with a $4.8 \%$ difference from the FEA results. The results from the experimental test verify that the microgripper's maximum displacement amplification ratio is approximately 58.2 times.
\end{abstract}

Keywords: Microgripper mechanism, Triple-stair half bridge-type, Grey relational analysis, Entropy weight, TO PSIS method.

\section{Introduction}

In the microscopic world, when manipulating with microparticles, the dexterity, accuracy, and speed of the manipulation will be improved when one can feel the interaction with the micro-part and controlled in real-time. The development of such a sensing micromanipulator system is of interest in many areas. For example, cell surgery, laparoscopic surgery, microrobots, and microassembly, etc[1-8]. The microgrippers developed based on the flexing properties of parts to create the desired movements include high precision motion, light, frictionless, and compactness, to name a few. These characteristics improved the effect of micro-manipulation operations. The micro-manipulation tasks can be realized with many kinds of actuation such as piezoelectric actuator, electrostatic, electromagnetic microgrippers,

Chia-Nan Wang

cn.wang@nkust.edu.tw

${ }^{1}$ Department Industrial Engineering Management, National Kaohsiung University of Science and Technology, Kaohsiung 80778, Taiwan R.O.C shape-memory alloy (SMA), electroactive polymers (EAPs) [9-15].

The piezoelectric actuator is normally used in the micro-grippers such as the operator because of its high force, high accuracy, high frequency operation, and small size[16-19]. Thus, it is widely applied in industrial fields such as robotics, micro-nano manufacturing. Long et al. 2017 [20] With the microgripper design used in bonding IC and LED is controlled by flexible PZT ceramic stack; Zubir et al. 2009 [21] used PZT ceramics for design a micro-gripper for micro-manipulation. Piezoelectric gripper is remarkable when applying in precision manipulating (Rakotondrabe and Ivan 2011) [22]. The sliding-mode control methodology was applied for piezoelectric drive, which overcomes the problem of parameters including effects of hysteresis and disturbance in piezoelectric drive systems without compensation (Liaw et al. 2008) [19]. Multi-layer piezoelectric materials were proposed for a large displacement and high force to expand its application possibilities (Yang and Xu 2017 
[23]; Wu and Xu 2018 [24]). Nachippan et al. (2018) [9] application model of piezoelectric microgripper for unmanned aircraft was also considered, analysis of the arbitrary variable structure of microgripper was performed and COMSOL MULTIPHYSICS 4.2 software was used for piezoelectric analysis. Research has shown that the material that creates piezoelectric microgripper also significantly affects the degree of movement of the mechanism, specifically compared to conventional materials such as silicon, polysilicon, and silicon dioxide. The result of Silicon dioxide is better than the other materials. The total displacement of the mechanism after structural modification showed a significant increase compared to the existing microgripper. Tilok Kumar Das et al. 2020 [25] The microgripper mechanism is based on a three levels of the displacement amplification mechanism used to expand the displacement of piezoelectric actuators, the ability to respond quickly to a frequency of $1044 \mathrm{~Hz}$.

The symmetric and asymmetric structural are applied to design the mechanism of micro-grippers. With symmetrical construction, most clamping mechanisms use the form of symmetrical construction, which has an advance in application of double-displacement amplification, and they can adapt to enlarge range of work clamping and assembling (Bao, et al, 2014)[26]. A singlestage microgripper with a symmetric structure based on the principle of lever amplification [27] was designed to fulfill the biggest displacement amplification but unable to achieve parallel clamping motion. Cui et al. [28], based on the rule to lever to design a symmetrical microgripper that could be complete the parallel clamping. However, the maximum actual output force between the both sides of the function are different, so it will lead to the destroy of the micro-component during the gripper clamping. Sun et al. [29] and Wang et al. [30] by using the principle of lever amplification and triangular gain, they designed a multiple-stage symmetrical microgripper, which could achieve parallel clamping of the grippers and bigger displacement amplification. However, the microgripper designed by them was unable to obtain a stable clamping motion. From above the review, it indicated that the movement of both of sides the microgripper cannot be achieve synchronized, so errors in the production and installation process cannot be avoided. Asynchronous motion is a mains limitation in symmetric structures. It affects the working quality as well as the precise position control. Thus, it requires motion binding to be able to control the movement of the two clamps simultaneously. To avoids the disadvantages of symmetric microgrippers, an asymmetrical structure is proposed to design with one side of the microgripper responsible for displacement while another side is unmoved. So there will be no nonsynchronization of the two gripper micro, and this is the most significant advantage of the types of asymmetric structure. On the other hand, there is also no asynchronous force during micro-component execution. Therefore, the micro parts will not be destroyed by unilateral force because only one clamp-side of the microgripper can be moved. Koo et al. [31] also based on the principle of lever amplification designed an microgripper with an asymmetric structure to achieve a stable grasp of the grippers, but unfortunately which could not grasp in parallel. Xing et al. [32] designed an asymmetric microgripper that could complete parallel grips of jaws. However, the structure has a small amplification. In addition, during the process fabrication of microgripper, the optimization of design parameters is necessary to get more efficient performance by eliminating unnecessary steps, saving time, reducing errors numbers, and avoid duplication of work. For example, the finite element model was simulated for optimization microgripper structure with consideration of the properties of PSA, nonlinear geometry limit, established static limit as well as dynamic bonding[33]. A hybrid Taguchi-teaching learning-based optimization algorithm (HTLBO) was used to optimize compliant microgrippers, the advantages of the hybrid approach are simplicity and fast computation, achievable desired optimal results [34]. Shunli Xiao et al [35] Optimize design parameters in the microsystem before fabrication is essential. The RBFN based multi-objective GA optimization method was applied to optimize the design parameters of the microgripper. The calculation process of an algorithm will receive the best set of solution variables, finally providing the best-suggested results to choose the parameters microgripper. Genetic algorithms have also been applied to solve the parameter appreciation problem of MEMS technique based on microgripper [36]. The Fuzzy-TOPSIS and Grey relationship analysis method was applied to select the optimal cutting parameter values [37]. Fuzzy TOPSIS can apply for the pick of optimal process parameters in micromanufacturing technology [38]. A new optimal selection method created by combining fuzzy set theory, the AHP, and TOPSIS was applied to the mining method selection which was then used to choose the most appropriate mining method for panel 43101 in the Liang-shuijing coal mine in China [39]. The best choice for various nontraditional machining processes using the integration of Fuzzy with AHP and QFD methods has been successfully made [40]. A new method combining NN - GA has been proposed and is applied to model and optimize the process parameters such as pulse width, pulse frequency, cutting speed, and gas pressure of Ti-Alloy plate cutting pulse laser [41]. Aside from this, multi-criteria decision-making (MCDM) is gaining popularity in renewable energy systems. The evaluation, selection, and ranking of renewable energy systems in Turkey will have many incompatible criteria causing difficulties in the research 
process. The proposed Entropy weight, Fuzzy-TOPSIS methods are applied to support quick and efficient process decision-making [42].

In this paper, a detailed parametric study was conducted to analyze the influence of various geometrical parameters such as incline angle $(\alpha)$, thickness $(t)$, length (l) of the flexure hinge for the output displacement amplification ratio, and the stress of the microgripper structure. Give selected to the optimal design variables to achieve maximum displacement, minimizing microgripper stress. So, multi-objective optimization was conducted using the TOPSIS method based on the GRA technique with entropy measurement method to optimize the output parameters of the compliance mechanism. Finally, verification experiments were conducted to confirm the optimal results obtained.

\section{Structural design and methodology}

\subsection{Structural design of model}

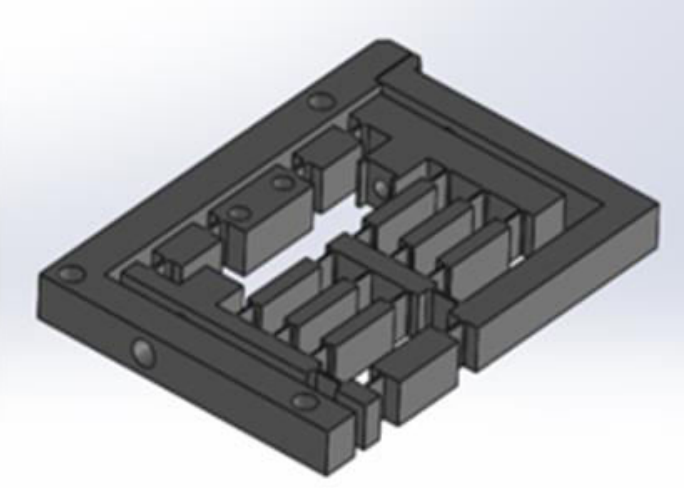

(a)
The dimension of the specimen microgripper is $110 \mathrm{~mm} \times 78 \mathrm{~mm} \times 10 \mathrm{~mm}$. The $2 \mathrm{D}$ and $3 \mathrm{D}$ factors used to model the microgripper mechanism has shown in Figure 1. The asymmetric structure has proposed to develop a piezoelectric actuator microgripper based on a compact flexure hinge. The microgripper construction uses a corner-filleted flexure hinge, a fixed jaw, a moving function, and a piezoelectric actuator (PZT).

Additionally, a two-stage amplifier included a triplebridge amplifier and a single lever amplifier was designed to improve the clamping stroke and obtain the highest output displacement. The triple-bridge-type amplifier and the lever amplifier were directly connected in series to obtain a bigger displacement amplification. The structure of the triple-stairs was choosing to develop a compact flexure hinge-based piezoelectric actuator microgripper. With a triple-stair structure the stiffness of the model will be increased, which can withstand a greater input force and adopted at a higher frequency than a single-stair and double-stair structure. Besides, it still ensures a large output amplifier displacement.

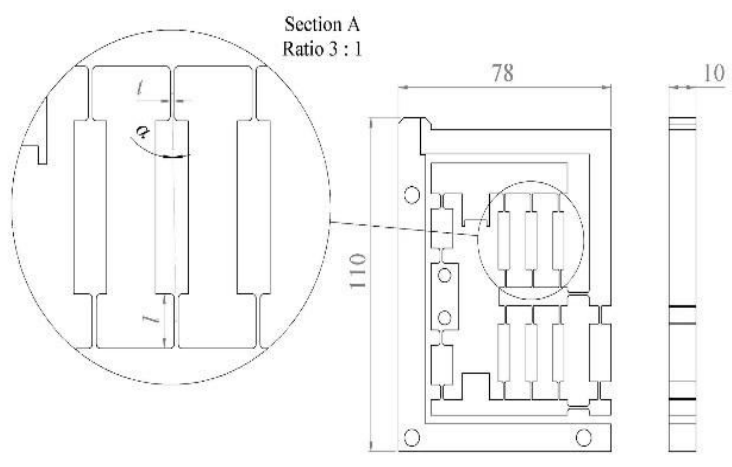

(b)

Figure 1. Model design

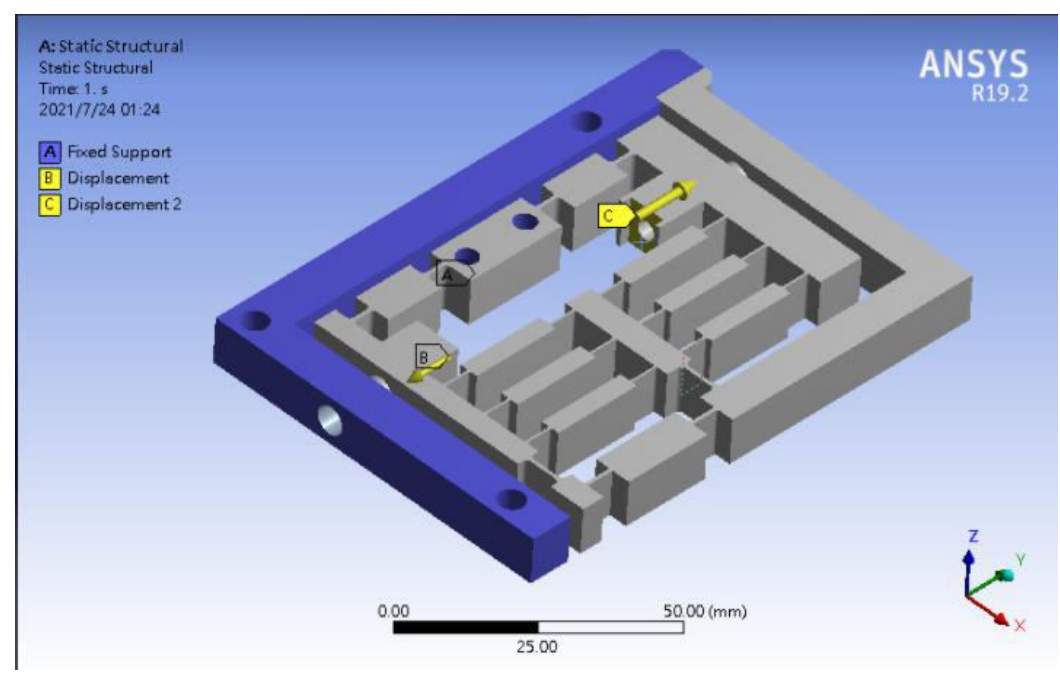

Figure 2. The input setting 


\subsection{Finite element method simulation}

The characteristics of PLA is showed in Table 1. The density is $1.25 \mathrm{Mg} / \mathrm{m}^{3}$. The model was designed by using Autodesk Inventor software and was analyzed by FEA embedded in ANSYS.

Table 1. Material mechanical properties.

\begin{tabular}{|c|c|}
\hline Material & PLA \\
\hline Tensile strength & $55 \mathrm{MPa}$ \\
\hline Young's modulus & $3.5 \mathrm{GPa}$ \\
\hline Shear modulus & $40 \mathrm{GPa}$ \\
\hline
\end{tabular}

The Fixed support is used for three holes outside and two holes inside. The displacement input controlled by the piezoelectric actuator is shown in Figure 2.

\section{Optimal method}

\subsection{Design simulation}

The Taguchi experimental design involves three factors with three levels, L27 orthogonal arrays were used to conduct the simulation. The levels of each factor are shown as Table 2. The observed responses are displacement of the output of one side of the microgripper function in the $\mathrm{x}$-axis, and stress within the model. Table 3 shows the experimental layout and results.

Table 2. Material mechanical properties.

\begin{tabular}{|c|c|c|c|}
\hline \multirow{2}{*}{ Factor } & \multicolumn{3}{|c|}{ Levels } \\
\cline { 2 - 4 } & 1 & 2 & 3 \\
\hline Incline angle of FXH $(\alpha$, degree $)$ & 1 & 1.1 & 1.2 \\
\hline Length of FXH $(l, \mathrm{~mm})$ & 4 & 5 & 6 \\
\hline Thickness of FXH $(t, \mathrm{~mm})$ & 0.3 & 0.4 & 0.5 \\
\hline
\end{tabular}

\subsection{Grey relational analysis method}

The Grey theory [43] is widely applied to the system whose model is uncertain or lack of information. It supplies an effective solution to the problem of uncertainty and multiple discrete inputs. GRA based on grey theory is well known for its suitability about solving multiple factors (Mora' n, Granada, Míguez, \& Porteiro, 2006) [44]. GRA was useful to analyze a variety of MADM problems (Olson \& Wu, 2006) [45]. The initial problem is to reduce the issue into a single property decision making. Similar with the procedure applied in TOPSIS, integrating all properties values into a single value. In the first step of GRA process called grey rationalization, it normalizes the input value from 0 to 1 for testing data. Then for the second step, based on the normalized experimental data, calculating the grey relation coefficients to represent the correlation between the desirable data and actual experimental data. At the final, calculate the average GRC of selected cases to determine the overall grey relation grade. The grey relation grade can indicate the impact performance and characteristic of parameters during the multi-response process. Then, based on the signal to noise $(\mathrm{S} / \mathrm{N})$ ratio of Taguchi method, the parameters configuration with the highest GRG can be considered as the optimal solution for the case and determine the quality characteristics.

The equation about the $\mathrm{S} / \mathrm{N}$ ratio is shown in the below formula:

$$
\mathrm{S} / \mathrm{N}=10 \log \left(\frac{1}{n} \sum_{i=1}^{n} y_{i}^{2}\right)
$$

Table 3. Experimental layout and simulation results.

\begin{tabular}{|c|c|c|c|c|c|}
\hline No. & $\alpha$ & $l$ & $t$ & Displacement & Stress \\
\hline 1 & 1 & 4 & 0.3 & 0.5818 & 2.4316 \\
\hline 2 & 1 & 4 & 0.4 & 0.45164 & 2.4234 \\
\hline 3 & 1 & 4 & 0.5 & 0.35041 & 2.5329 \\
\hline 4 & 1 & 5 & 0.3 & 0.48125 & 2.4266 \\
\hline 5 & 1 & 5 & 0.4 & 0.45961 & 2.5419 \\
\hline 6 & 1 & 5 & 0.5 & 0.3606 & 2.5386 \\
\hline 7 & 1 & 6 & 0.3 & 0.57452 & 2.4723 \\
\hline 8 & 1 & 6 & 0.4 & 0.46087 & 2.5598 \\
\hline 9 & 1 & 6 & 0.5 & 0.36491 & 2.5642 \\
\hline 10 & 1.1 & 4 & 0.3 & 0.58232 & 2.5913 \\
\hline 11 & 1.1 & 4 & 0.4 & 0.45999 & 2.6012 \\
\hline 12 & 1.1 & 4 & 0.5 & 0.36083 & 2.5314 \\
\hline 13 & 1.1 & 5 & 0.3 & 0.58149 & 2.6577 \\
\hline 14 & 1.1 & 5 & 0.4 & 0.46765 & 2.6007 \\
\hline 15 & 1.1 & 5 & 0.5 & 0.37098 & 2.6134 \\
\hline 16 & 1.1 & 6 & 0.3 & 0.57465 & 2.6431 \\
\hline 17 & 1.1 & 6 & 0.4 & 0.46864 & 2.6253 \\
\hline 18 & 1.1 & 6 & 0.5 & 0.37521 & 2.6311 \\
\hline 19 & 1.2 & 4 & 0.3 & 0.57899 & 2.7676 \\
\hline 20 & 1.2 & 4 & 0.4 & 0.46495 & 2.6902 \\
\hline 21 & 1.2 & 4 & 0.5 & 0.3692 & 2.6247 \\
\hline 22 & 1.2 & 5 & 0.3 & 0.57787 & 2.7482 \\
\hline 23 & 1.2 & 5 & 0.4 & 0.47213 & 2.749 \\
\hline 24 & 1.2 & 5 & 0.5 & 0.37903 & 2.648 \\
\hline 25 & 1.2 & 6 & 0.3 & 0.57121 & 2.7339 \\
\hline 26 & 1.2 & 6 & 0.4 & 0.47286 & 2.6503 \\
\hline 27 & 1.2 & 6 & 0.5 & 0.3831 & 2.5987 \\
\hline
\end{tabular}

In this study, the GRA is used to analyze the multiresponse characteristics in the optimization procedure. The steps are shown as below:

Step 1: Normalize data

The smaller-the-better case is computed as: 


$$
x_{i}^{*}(k)=\frac{\max x_{i}^{0}(k)-x_{i}^{0}(k)}{\max x_{i}^{0}(k)-\min x_{i}^{0}(k)}
$$

The larger-the-better case is computed as:

$$
x_{i}^{*}(k)=\frac{x_{i}^{0}(k)-\min x_{i}^{0}(k)}{\max x_{i}^{0}(k)-\min x_{i}^{0}(k)}
$$

The normalized-the-better case is computed as:

$$
x_{i}^{*}(k)=1-\frac{x_{i}^{0}(k)-x_{0}}{\max x_{i}^{0}(k)-x_{0}}
$$

Following the requirement in this study, the stress was chosen as "smaller-the- better". The displacement was chosen as the "larger-the-better".

Where $x_{i}^{*}(k)$ is the value after normalized value, $\max \left(x_{i}^{0}(k)\right)$ and $\min \left(x_{i}^{0}(k)\right)$ are the highest and lowest value of $x_{i}^{0}(k)$ for the $k^{t h}$ response, respectively, $\mathrm{k}$ being 1 for displacement, 2 for stress.

While the value has been normalized, they will range from 0 to 1 , and the larger the result value is, the better the performance will be.

Step 2: GRC calculation

The connection with the ideal and the actual experiment results is shown as GRC $\xi_{i}(\mathrm{k})$ which is calculated by below equation:

$$
\xi_{i}=\frac{\Delta_{\min }+\zeta \Delta_{\max }}{\Delta_{o i}(k)+\zeta \Delta_{\max }}\left(0<\xi_{i}(k) \leq 1\right)
$$

Where $\Delta_{o i}(k)$ is the deviation array of reference array $x_{i}^{0}(k)$ and comparability array $x_{i}^{*}(k)$ :

$$
\begin{aligned}
& \Delta_{o i}=\left\|x_{0}^{*}(k)-x_{i}^{*}(k)\right\| \\
& \Delta_{\min }=\min _{\forall j \in i \forall k}\left\|x_{0}^{*}(k)-x_{i}^{*}(k)\right\| \\
& \Delta_{\max }=\operatorname{maxmax}_{\forall j \in i \forall k}\left\|x_{0}^{*}(k)-x_{i}^{*}(k)\right\|
\end{aligned}
$$

$\zeta$ is the distinguishing coefficient $(\xi \in[0,1])$ used to tune up the difference of the relational coefficient. Its value was chosen as 0.5 and the GRC is calculated using equation (3).

Step 3: GRG is computed by averaging the corresponding grey relational coefficients.

$$
\gamma_{i}=\frac{\sum_{n}^{k=1} w_{k} \xi_{i}(k)}{\sum_{n}^{k=1} w_{k}}
$$

Where $\mathrm{w}_{-} \mathrm{k}$ is normalized weight of element $\mathrm{k}$ according to the real situation of various factor.

\subsection{Entropy method}

Using the probability theory can formulate and determine uncertain information (Wen et al. [46]). And entropy method can be used to derive the weights and the entropy $\left(E_{j}\right)$ that are calculated by follow equations:

Step 1: Calculate the summation of each attribute's value for all array, $D_{k}$ (Sum of the GRC in all sequences)

$$
D_{k}=\sum_{i=1}^{m} x_{i}(k)
$$

Step 2: Figure out the entropy of the specific attribute, $e_{k}$

$$
e_{k}=K \sum_{i=1}^{m} W_{e}\left(P_{i}\right)
$$

Where

$$
\begin{gathered}
\text { We }\left(P_{i}\right)=p_{i} * e^{\left(1-p_{i}\right)}+\left(1-p_{i}\right) * e^{p_{i}} \\
-1 ;\left(p_{i}=\frac{x_{i}(k)}{D_{k}}\right) \\
K=\frac{1}{\left(e^{0.5}-1\right) * m}
\end{gathered}
$$

Step 3: Calculate the total entropy value $\mathrm{E}$

$$
E=\sum_{k=1}^{n} e_{k}
$$

Step 4: Determine the relative weighting factor, $\beta_{k}$

$$
\beta_{k}=\frac{1}{n-E}\left(1-e_{k}\right)
$$

Step 5: The normalized weight of each attribute can be calculated by

$$
w_{k}=\frac{\beta_{k}}{\sum_{k=1}^{n} \beta_{k}}
$$

\subsection{TOPSIS method}

The TOPSIS (Lai, Liu, \& Hwang, 1994) [47] is one of the classical Multi-Criteria Decision Matrix (DMs) methods, it was developed the first time by Hwang and Yoon [48]. TOPSIS, be advantage of its capacity to define the best alternative rapidly, is an attractive ranking technique that only requires limited thematic input. In order to appreciate the distance between data series, the decision matrix in the TOPSIS process is formed by the grey coefficients in this study. The TOPSIS method is shown as below [48]

Step 1: The DMs is presented as below matrix

$$
\mathrm{A}=\left(a_{i j}\right)_{m x n}=\left[\begin{array}{lllr}
a_{11} & a_{12} & \ldots & a_{1 n} \\
a_{21} & a_{21} & \ldots & a_{2 n} \\
\cdots & \ldots & \ldots & \ldots \\
a_{m 1} & a_{m 2} & \ldots & a_{m n}
\end{array}\right]
$$

Where $\mathrm{n}$ is the quantity of variables and $a_{i j}$ is the value of GRC.

The equation is used to normalize each attribute value $a_{i j}$ in DMs $\mathrm{A}=\left(a_{i j}\right)_{m x n}$ into a correlate factor $g_{i j}$ in a normalized DMs as

$$
\mathrm{G}=\left(g_{i j}\right)_{m x n}=\left[\begin{array}{cccc}
g_{11} & g_{12} & \cdots & g_{1 n} \\
g_{21} & g_{22} & \ldots & g_{2 n} \\
\vdots & \vdots & \vdots & \vdots \\
g_{m 1} & g_{m 2} & \ldots & g_{m n}
\end{array}\right]
$$

Where 
$g_{i j}=\frac{a_{i j}}{\sqrt{\sum_{1}^{m}\left(a_{i j}\right)^{2}}}, i \in\{1,2, \ldots, m\}, j \in\{1,2, \ldots, n\}$

Step 2: Calculate the weighted standardized DMs

$$
\mathrm{Z}=\left(w_{j} g_{i j}\right)_{m x n}
$$

Where, the weights $\left(w_{j}\right)$ are calulated by the Entropy Method [46].

Step 3: Calculate the positive ideal solution (PIS, $D^{+}$) and negative ideal solution (NIS, $D^{-}$).

\begin{tabular}{|l|l|}
\hline$D^{+}=\left\{z_{1}^{+}, z_{2}^{+}, \ldots, z_{i}^{+}\right\}, z_{j}^{+}=\max _{1 \leq i \leq m}\left\{z_{i j}\right\}, \mathrm{j} \in N$ & $(21)$ \\
\hline$D^{-}=\left\{z_{1}^{-}, z_{2}^{-}, \ldots, z_{i}^{-}\right\}, z_{j}^{-}=\max _{1 \leq i \leq m}\left\{z_{i j}\right\}, \mathrm{j} \in N$ & (22) \\
\hline
\end{tabular}

Step 4: Calculate the root-mean square error (RMSE) of target position with positive ideal (PI) position and negative ideal (NI) position by using the Euclidean distance.

The derived PIS $S_{i}^{+}$is shown as follows

$$
S_{i}^{+}=\sqrt{\sum_{i=1}^{n}\left(z_{i j}-z_{j}^{+}\right)^{2}}, i \in\{1,2, \ldots, m\}
$$

The derived NIS $S_{i}^{-}$is shown as follows

$$
S_{i}^{-}=\sqrt{\sum_{i=1}^{n}\left(z_{i j}-z_{j}^{-}\right)^{2}}, i \in\{1,2, \ldots, m\}
$$

Where $S_{i}^{+}$and $S_{i}^{-}$can be also considered as the distances of the $i^{\text {th }}$ alternative with PI and NI solution.

Step 5: Calculate the coefficient closest to the ideal solutions.

The nearness coefficient of the $i^{\text {th }}$ alternative $D_{i}$ with correlation to the ideal solution is shown as

$$
C_{i}=\frac{S_{i}^{-}}{S_{i}^{+}+S_{i}^{-}}, i \in\{1,2, \ldots, m\}
$$

Step 6: The ranking order and valuation.

The priority of alternatives can be sorted in a descending order according to $C_{i}$, and the higher $C_{i}$ implies better choice.

\subsection{Hybrid GTs-TOPSIS method}

The hybrid optimization method can simplify data processing procedure, time reduction, and provide the user to determine a more efficient method to select the most appropriate criteria. For example: Kai Zhang et al., (2019) [49] came out with a DMs problem in a fuzzycovered approximation space and solved it by the TOPSIS method. First of all, integrating a fuzzy proximity operator with a fuzzy coarse set model, two pairs of fuzzy coarse set models based on overlapping and studying basic characteristics together with the classification of these two pairs of models. Then, a new method to specify the target weights using a pair of fuzzy coarse models based on the first overlay. In order to solve the material selection problem, take advantage of the fuzzy rough set in processing uncertain data and the method of determining objective criteria weights with TOPSIS, integrating the both methods to propose a new multi-criteria decision-making method. Behnam Vahdani et al. (2011) [50] The combination of fuzzy and TOPSIS method has been studied and used as the right decision tool for choosing the optimal solution to the problems of selecting robots and rapid prototyping in production.

TOPSIS, an attractive ranking technique, whose advantage is the ability to identify the best alternative faster with just limited subject input. In this study, the grey coefficients are used to build up the decisions making matrix in the TOPSIS procedure to evaluate the range between the data chain. The calculation process is shown in Figure 3.

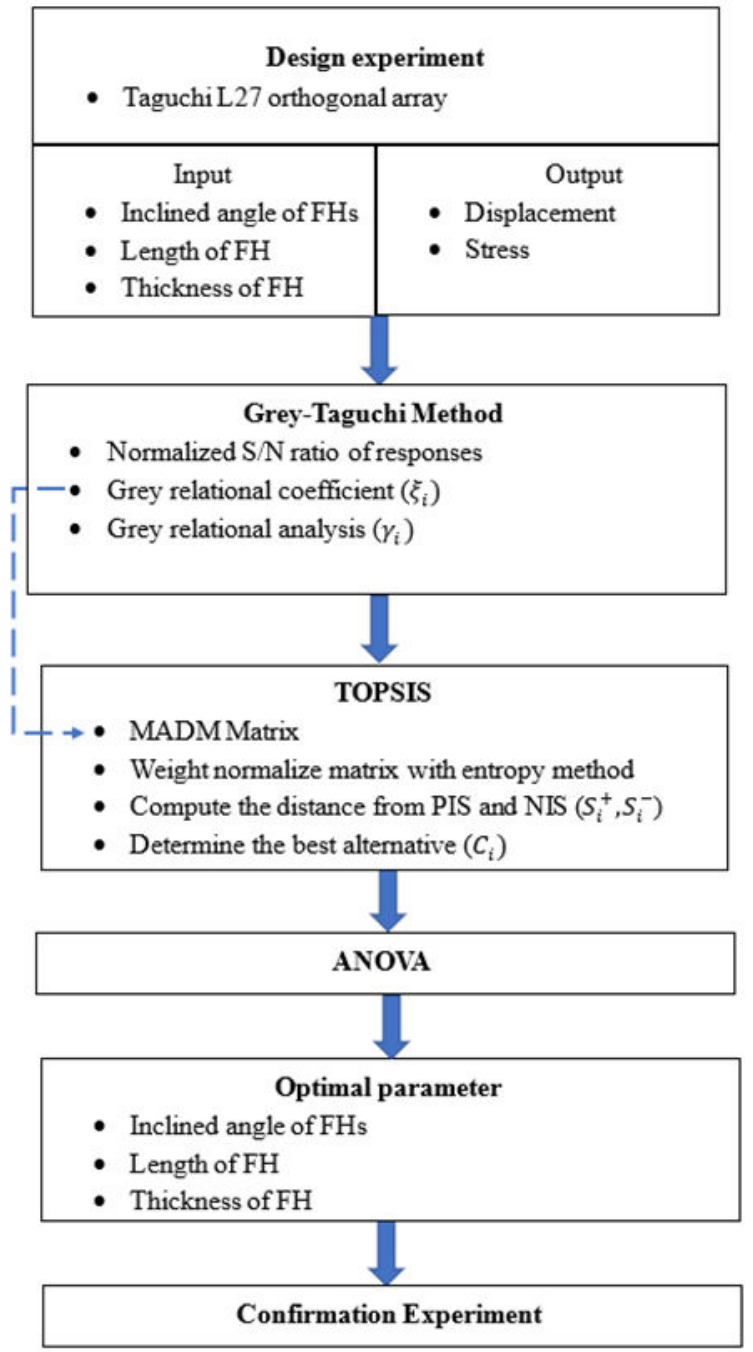

Figure 3. The flow chart of combining GTs-TOPSIS.

\section{Result and discussion}

\subsection{Grey relational grade-Taguchi (GTs)}

The first normalize the initial data values to the range of values [0-1], the feedback value of the chosen displacement amplifier is as large as possible, the stress 
value is the smaller-the better. Data normalized results results calculations are presented in Table 4 as follows. using formulas (1) and (2). The second, the deviation sequences $\Delta$ oi are calculated by equation (5-7). The 
Table 4. The data normalize and deviation sequences of each individual quality characteristic.

\begin{tabular}{|c|c|c|c|c|}
\hline \multirow{2}{*}{ No. } & \multicolumn{2}{|c|}{$\boldsymbol{x}_{\boldsymbol{i}}^{*}(\boldsymbol{k})$} & \multicolumn{2}{c|}{$\Delta \mathbf{i}$} \\
\cline { 2 - 5 } & Displacement & Stress & Displacement & Stress \\
\hline 1 & 0.9978 & 0.9762 & 0.0022 & 0.0238 \\
\hline 2 & 0.4365 & 1.0000 & 0.5635 & 0.0000 \\
\hline 3 & 0.0000 & 0.6819 & 1.0000 & 0.3181 \\
\hline 4 & 0.5642 & 0.9907 & 0.4358 & 0.0093 \\
\hline 5 & 0.4709 & 0.6557 & 0.5291 & 0.3443 \\
\hline 6 & 0.0439 & 0.6653 & 0.9561 & 0.3347 \\
\hline 7 & 0.9664 & 0.8579 & 0.0336 & 0.1421 \\
\hline 8 & 0.4763 & 0.6037 & 0.5237 & 0.3963 \\
\hline 9 & 0.0625 & 0.5909 & 0.9375 & 0.4091 \\
\hline 10 & 1.0000 & 0.5122 & 0.0000 & 0.4878 \\
\hline 11 & 0.4725 & 0.4834 & 0.5275 & 0.5166 \\
\hline 12 & 0.0449 & 0.6862 & 0.9551 & 0.3138 \\
\hline 13 & 0.9964 & 0.3193 & 0.0036 & 0.6807 \\
\hline 14 & 0.5055 & 0.4849 & 0.4945 & 0.5151 \\
\hline 15 & 0.0887 & 0.4480 & 0.9113 & 0.5520 \\
\hline 16 & 0.9669 & 0.3617 & 0.0331 & 0.6383 \\
\hline 17 & 0.5098 & 0.4134 & 0.4902 & 0.5866 \\
\hline 18 & 0.1069 & 0.3966 & 0.8931 & 0.6034 \\
\hline 19 & 0.9856 & 0.0000 & 0.0144 & 1.0000 \\
\hline 20 & 0.4939 & 0.2249 & 0.5061 & 0.7751 \\
\hline 21 & 0.0810 & 0.4152 & 0.9190 & 0.5848 \\
\hline 22 & 0.9808 & 0.0564 & 0.0192 & 0.9436 \\
\hline 23 & 0.5249 & 0.0540 & 0.4751 & 0.9460 \\
\hline 24 & 0.1234 & 0.3475 & 0.8766 & 0.6525 \\
\hline 25 & 0.9521 & 0.0979 & 0.0479 & 0.9021 \\
\hline 26 & 0.5280 & 0.3408 & 0.4720 & 0.6592 \\
\hline 27 & 0.1410 & 0.4907 & 0.8590 & 0.5093 \\
\hline
\end{tabular}

Then, the distinguishing coefficient $\zeta$ is used to adjust the range of the comparison environment, which can be substituted for the grey relational coefficient in equation (4), in this study $\zeta$ was taken as 0.5 . The last step is determining the grey relational grade coefficient, based on formula (8), the grey relational grade coefficient has been determined and the results are presented in Table 5 . In this study, the weight of each factor after applying the formula in the entropy method [46] is 0.5002 and 0.4998 , respectively.
The larger the GRG is the performance characteristics possible. From Table 5 and Figure 4, it shows that experiment 1 had the highest GRG of 0.726 among experiments. Thus, experiment 1 was the best performance among the 27 experiments. At experiment number one with flexure hinge geometry parameters: thickness is $0.3 \mathrm{~mm}$, length is $4 \mathrm{~mm}$, and incline angle is 1 degree. The large output amplifier displacement ratio is 58 time, and the stress is $2.4316 \mathrm{MPa}$. 
Table 5. Calculated for GRC, GRG and rank of displacement and stress.

\begin{tabular}{|c|c|c|c|c|}
\hline \multirow{2}{*}{ S. No } & \multicolumn{2}{|c|}{ GRC } & \multirow{2}{*}{ GRG } & \multirow{2}{*}{ Rank } \\
\hline & Displacement & Stress & & \\
\hline 1 & 0.9955 & 0.9545 & 0.9750 & 1 \\
\hline 2 & 0.4701 & 1.0000 & 0.7351 & 5 \\
\hline 3 & 0.3333 & 0.6112 & 0.4722 & 18 \\
\hline 4 & 0.5343 & 0.9817 & 0.7580 & 4 \\
\hline 5 & 0.4858 & 0.5922 & 0.5390 & 11 \\
\hline 6 & 0.3434 & 0.5990 & 0.4712 & 19 \\
\hline 7 & 0.9370 & 0.7787 & 0.8579 & 2 \\
\hline 8 & 0.4884 & 0.5579 & 0.5231 & 12 \\
\hline 9 & 0.3478 & 0.5500 & 0.4489 & 20 \\
\hline 10 & 1.0000 & 0.5062 & 0.7531 & 3 \\
\hline 11 & 0.4866 & 0.4919 & 0.4892 & 14 \\
\hline 12 & 0.3436 & 0.6144 & 0.4790 & 16 \\
\hline 13 & 0.9929 & 0.4235 & 0.7082 & 6 \\
\hline 14 & 0.5028 & 0.4926 & 0.4977 & 13 \\
\hline 15 & 0.3543 & 0.4753 & 0.4148 & 24 \\
\hline 16 & 0.9380 & 0.4393 & 0.6886 & 7 \\
\hline 17 & 0.5050 & 0.4602 & 0.4826 & 15 \\
\hline 18 & 0.3589 & 0.4531 & 0.4060 & 26 \\
\hline 19 & 0.9721 & 0.3333 & 0.6527 & 9 \\
\hline 20 & 0.4970 & 0.3921 & 0.4445 & 21 \\
\hline 21 & 0.3524 & 0.4609 & 0.4066 & 25 \\
\hline 22 & 0.9630 & 0.3463 & 0.6547 & 8 \\
\hline 23 & 0.5127 & 0.3458 & 0.4293 & 23 \\
\hline 24 & 0.3632 & 0.4338 & 0.3985 & 27 \\
\hline 25 & 0.9126 & 0.3566 & 0.6346 & 10 \\
\hline 26 & 0.5144 & 0.4313 & 0.4729 & 17 \\
\hline 27 & 0.3679 & 0.4954 & 0.4140 & 22 \\
\hline
\end{tabular}

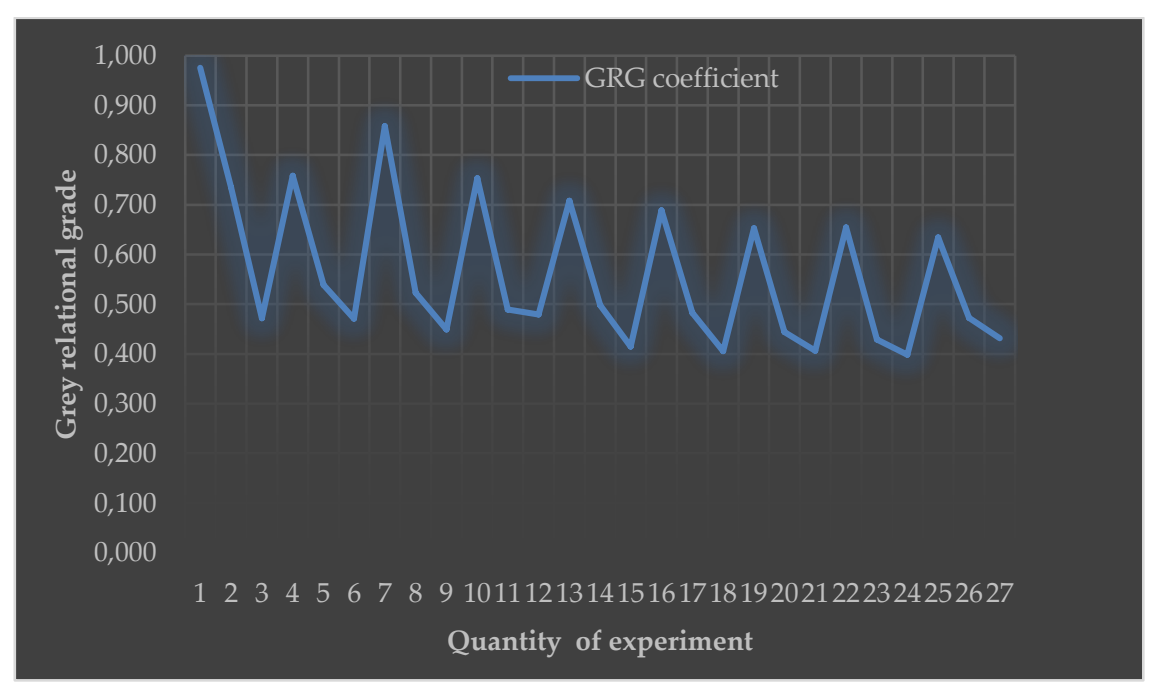

Figure 4. The results of grey relational grade (GRG) of the experiments. 
Calculating the $\mathrm{S} / \mathrm{N}$ ratio to analyze the optimal level for each parameter $t, 1$, and $\alpha$, respectively. The optimal configuration of the flexure hinge dimension parameters was observed as $1_{1} t_{1} \alpha_{1}$. The results were shown in the Table 6. And the main effects and interaction plot for mean for GRG are shown in Figure 5.

Table 6. Signal to Noise Ratios (S/N)

\begin{tabular}{|c|c|c|c|}
\hline \multirow{2}{*}{ Level } & \multicolumn{3}{|c|}{ Parameter } \\
\cline { 2 - 4 } & Incline angle & Length & Thickness \\
\hline 1 & -4.182 & -4.782 & -2.666 \\
\hline 2 & -5.463 & -5.559 & -5.907 \\
\hline 3 & -6.188 & -5.492 & -7.26 \\
\hline
\end{tabular}

Hence, the best combination values for maximizing the multiple performance characteristics were thickness of $0.3 \mathrm{~mm}$, the length of $4 \mathrm{~mm}$ and incline angle of 1 degree. The response table for the means of GRG is shown in Table 7.

Analysis of variance (ANOVA) output of the multiple performance characteristics are given in Table 8 . The referred confidence and significance level were 0.95 and 0.05 , respectively.

As shown in Table 8, the thickness and incline angle of the flexure hinge were remarkable factors, and the interaction of the thickness with the incline angle also had significant value. The thickness had the largest contribution ratio as $72.73 \%$ to the flexure hinge. Furthermore, the contribution of incline angle and length was $14.78 \%$ and $3.04 \%$, respectively. Thus, the variation of thickness of flexure hinge will affect significantly on the displacement amplifier based on the preferred criteria output. R squared was calculated as $97.12 \%$, which can be considered as the suitability of this linear regression model.

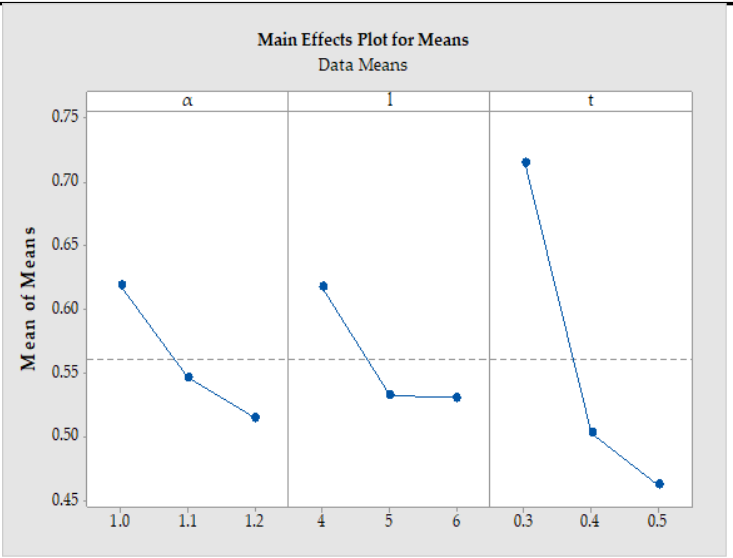

(a)

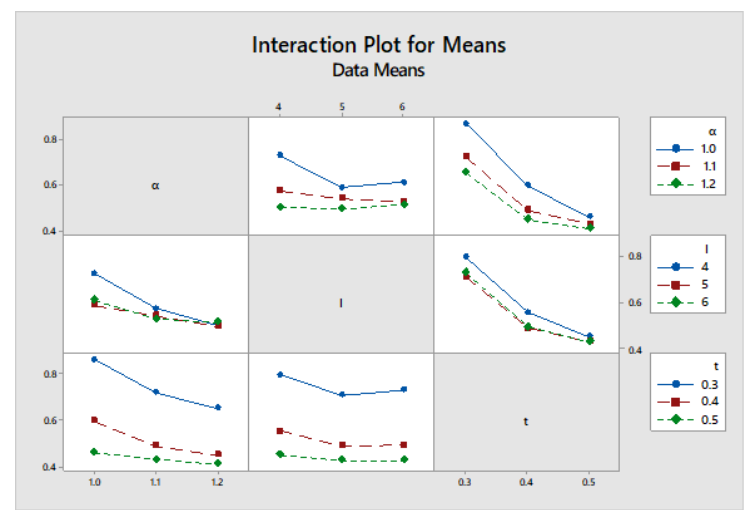

(b)

Figure 5. Main effects plot for means and interaction plot for mean.

Table 7. Response Table for Mean for GRG

\begin{tabular}{|c|c|c|c|}
\hline \multirow{2}{*}{ Level } & \multicolumn{3}{|c|}{ Parameter } \\
\cline { 2 - 4 } & Incline angle & Length & Thickness \\
\hline 1 & 0.6423 & 0.6008 & 0.7425 \\
\hline 2 & 0.5466 & 0.5413 & 0.5126 \\
\hline 3 & 0.5009 & 0.5476 & 0.4346 \\
\hline
\end{tabular}

Table 8. Analysis of variance (ANOVA) result.

\begin{tabular}{|c|c|c|c|c|c|c|c|}
\hline Source & DF & Seq SS & Contribution & Adj SS & Adj MS & F-Value & P-Value \\
\hline$\alpha$ & 2 & 0.0937 & $14.78 \%$ & 0.0937 & 0.0469 & 20.53 & 0.001 \\
\hline 1 & 2 & 0.0193 & $3.04 \%$ & 0.0193 & 0.0096 & 4.22 & 0.056 \\
\hline $\mathrm{t}$ & 2 & 0.4613 & $72.73 \%$ & 0.4613 & 0.2307 & 101.04 & 0.000 \\
\hline$\alpha^{*} 1$ & 4 & 0.0179 & $2.82 \%$ & 0.0179 & 0.0045 & 1.96 & 0.194 \\
\hline$\alpha^{*} \mathrm{t}$ & 4 & 0.0206 & $3.25 \%$ & 0.0206 & 0.0052 & 2.26 & 0.152 \\
\hline $1 * \mathrm{t}$ & 4 & 0.0032 & $0.50 \%$ & 0.0032 & 0.0008 & 0.35 & 0.837 \\
\hline Error & 8 & 0.0183 & $2.88 \%$ & 0.0183 & 0.0023 & & \\
\hline Total & 26 & 0.6343 & $100.00 \%$ & \multicolumn{7}{|l}{} \\
\hline R-sq & $97.12 \%$ & \multicolumn{7}{|l}{} \\
\hline
\end{tabular}

\subsection{Combine GTs-TOPSIS}

The first step was to classify the attributes and alternatives as the parameter inputs and response outputs of the experiment. Its values are substituted into the
GRC, placed to the decision matrix A.

The decision matrix $A$ and matrix $G$ were normalized by equation (17) and (18). Besides, the equation (19) can be used to compute the benefit attribute. The value of two attributes are inversely proportional that meant when one of the attributes decreased, the other will increase. 
Additionally, the value of change is the same. In this paper, the benefit attribute was used for analysis and the entropy method was applied to specify the attribute weight by using equations (10) - (16) sequentially. The results are shown in Table 9. Matrix $\mathrm{Z}$ was calculated by Equation (20) with attribute weight $w_{j}=\left[\begin{array}{ll}0.5002 & 0.4998\end{array}\right]^{T}$.

Table 9. Decision matrix

\begin{tabular}{|c|c|c|c|c|c|c|}
\hline \multirow{3}{*}{ No. } & \multicolumn{2}{|c|}{ Matrix A } & \multirow{2}{*}{\multicolumn{2}{|c|}{$\begin{array}{l}\text { Matrix G } \\
\text { Attribute }\end{array}$}} & \multirow{2}{*}{\multicolumn{2}{|c|}{ Matrix $Z=\left(w_{j} p_{i j}\right)_{m x n}$}} \\
\hline & \multicolumn{2}{|c|}{ GRC } & & & & \\
\hline & Displacement & Stress & Displacement & Stress & Displacement & Stress \\
\hline 1 & 0.9955 & 0.9545 & 0.2994 & 0.3222 & 0.4979 & 0.4771 \\
\hline 2 & 0.4701 & 1.0000 & 0.1414 & 0.3376 & 0.2352 & 0.4998 \\
\hline 3 & 0.3333 & 0.6112 & 0.1003 & 0.2063 & 0.1667 & 0.3055 \\
\hline 4 & 0.5343 & 0.9817 & 0.1607 & 0.3314 & 0.2672 & 0.4907 \\
\hline 5 & 0.4858 & 0.5922 & 0.1461 & 0.1999 & 0.2430 & 0.2960 \\
\hline 6 & 0.3434 & 0.5990 & 0.1033 & 0.2022 & 0.1718 & 0.2994 \\
\hline 7 & 0.9370 & 0.7787 & 0.2818 & 0.2629 & 0.4687 & 0.3892 \\
\hline 8 & 0.4884 & 0.5579 & 0.1469 & 0.1883 & 0.2443 & 0.2788 \\
\hline 9 & 0.3478 & 0.5500 & 0.1046 & 0.1857 & 0.1740 & 0.2749 \\
\hline 10 & 1.0000 & 0.5062 & 0.3008 & 0.1709 & 0.5002 & 0.2530 \\
\hline 11 & 0.4866 & 0.4919 & 0.1464 & 0.1660 & 0.2434 & 0.2458 \\
\hline 12 & 0.3436 & 0.6144 & 0.1034 & 0.2074 & 0.1719 & 0.3071 \\
\hline 13 & 0.9929 & 0.4235 & 0.2986 & 0.1430 & 0.4966 & 0.2117 \\
\hline 14 & 0.5028 & 0.4926 & 0.1512 & 0.1663 & 0.2515 & 0.2462 \\
\hline 15 & 0.3543 & 0.4753 & 0.1066 & 0.1604 & 0.1772 & 0.2376 \\
\hline 16 & 0.9380 & 0.4393 & 0.2821 & 0.1483 & 0.4691 & 0.2196 \\
\hline 17 & 0.5050 & 0.4602 & 0.1519 & 0.1553 & 0.2526 & 0.2300 \\
\hline 18 & 0.3589 & 0.4531 & 0.1080 & 0.1530 & 0.1795 & 0.2265 \\
\hline 19 & 0.9721 & 0.3333 & 0.2924 & 0.1125 & 0.4862 & 0.1666 \\
\hline 20 & 0.4970 & 0.3921 & 0.1495 & 0.1324 & 0.2486 & 0.1960 \\
\hline 21 & 0.3524 & 0.4609 & 0.1060 & 0.1556 & 0.1762 & 0.2304 \\
\hline 22 & 0.9630 & 0.3463 & 0.2897 & 0.1169 & 0.4817 & 0.1731 \\
\hline 23 & 0.5127 & 0.3458 & 0.1542 & 0.1167 & 0.2565 & 0.1728 \\
\hline 24 & 0.3632 & 0.4338 & 0.1092 & 0.1464 & 0.1817 & 0.2168 \\
\hline 25 & 0.9126 & 0.3566 & 0.2745 & 0.1204 & 0.4564 & 0.1782 \\
\hline 26 & 0.5144 & 0.4313 & 0.1547 & 0.1456 & 0.2573 & 0.2156 \\
\hline 27 & 0.3679 & 0.4954 & 0.1107 & 0.1672 & 0.1840 & 0.2476 \\
\hline
\end{tabular}

In the next step, Equations (21) and (22) are used to determine the positive and negative ideal solutions. Then the nearest alternative ranges from PIS and the farthest alternative range from NIS were computed by equations (23) and (24). The nearest coefficient is calculated by using equation (24). Finally, alternatives according to the value of $C_{i}$ was selected. The largest $C_{i}$ was the best choice. The resulting values are shown in Table 10 . According to the below result, the highest closeness coefficient was observed at the experiment number 1 , meaning that it was nearest to the ideal value.

Table 10. Nearness coefficient value and alternative ranking. 


\begin{tabular}{|c|c|c|c|c|}
\hline S. No & $S_{i}^{+}$ & $S_{i}^{-}$ & $C_{i}$ & Rank \\
\hline 1 & 0.0228 & 0.4540 & 0.9521 & 1 \\
\hline 2 & 0.2650 & 0.3402 & 0.5621 & 5 \\
\hline 3 & 0.3860 & 0.1389 & 0.2646 & 14 \\
\hline 4 & 0.2331 & 0.3393 & 0.5928 & 3 \\
\hline 5 & 0.3281 & 0.1502 & 0.3140 & 11 \\
\hline 6 & 0.3847 & 0.1329 & 0.2567 & 15 \\
\hline 7 & 0.1150 & 0.3751 & 0.7654 & 2 \\
\hline 8 & 0.3381 & 0.1364 & 0.2875 & 12 \\
\hline 9 & 0.3962 & 0.1085 & 0.2150 & 20 \\
\hline 10 & 0.2468 & 0.3445 & 0.5826 & 4 \\
\hline 11 & 0.3612 & 0.1103 & 0.2339 & 17 \\
\hline 12 & 0.3807 & 0.1406 & 0.2697 & 13 \\
\hline 13 & 0.2882 & 0.3330 & 0.5360 & 6 \\
\hline 14 & 0.3552 & 0.1163 & 0.2466 & 16 \\
\hline 15 & 0.4160 & 0.0717 & 0.1470 & 24 \\
\hline 16 & 0.2820 & 0.3070 & 0.5212 & 7 \\
\hline 17 & 0.3662 & 0.1067 & 0.2256 & 18 \\
\hline 18 & 0.4213 & 0.0612 & 0.1269 & 26 \\
\hline 19 & 0.3335 & 0.3195 & 0.4893 & 9 \\
\hline 20 & 0.3945 & 0.0870 & 0.1806 & 22 \\
\hline 21 & 0.4214 & 0.0645 & 0.1327 & 25 \\
\hline 22 & 0.3272 & 0.3150 & 0.4905 & 8 \\
\hline 23 & 0.4078 & 0.0900 & 0.1807 & 21 \\
\hline 24 & 0.4261 & 0.0524 & 0.1095 & 27 \\
\hline 25 & 0.3245 & 0.2900 & 0.4719 & 10 \\
\hline 26 & 0.3739 & 0.1030 & 0.2159 & 19 \\
\hline 27 & 0.4044 & 0.0828 & 0.1700 & 23 \\
\hline
\end{tabular}

The optimal parameter was verified at $l_{1}, t_{1}, \alpha_{1}$. The Taguchi technique was proposed to find the great value. The result is shown in Table 11.

Table 11. The s/n ratio of GTS-TOPSIS

\begin{tabular}{|c|c|c|c|}
\hline \multirow{2}{*}{ Level } & \multicolumn{3}{|c|}{ Parameter } \\
\cline { 2 - 4 } & Incline angle & Length & Thickness \\
\hline 1 & -4.182 & -4.782 & -2.666 \\
\hline 2 & -5.463 & -5.559 & -5.907 \\
\hline 3 & -6.188 & -5.492 & -7.26 \\
\hline
\end{tabular}

The $\mathrm{S} / \mathrm{N}$ ratio data and raw data provided the same optimal level by drawing the main effects plot. The result is shown in Figure 6

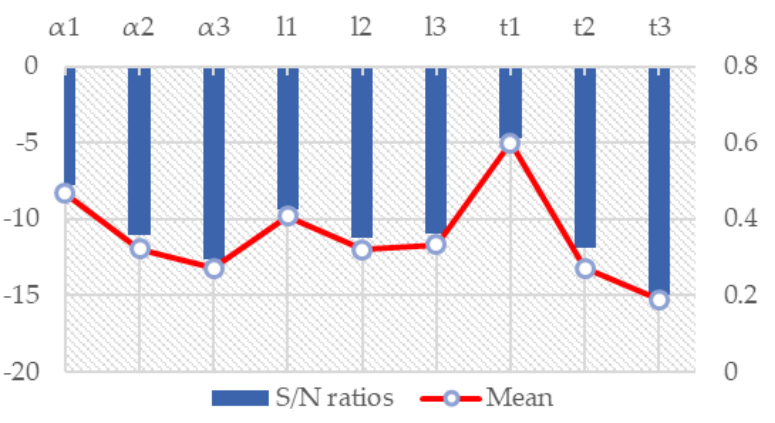

Figure 6. The main effect plot for mean and $\mathrm{S} / \mathrm{N}$ ratios The main effects and interaction plot for mean for GTs-TOPSIS are shown in Figure 7. 


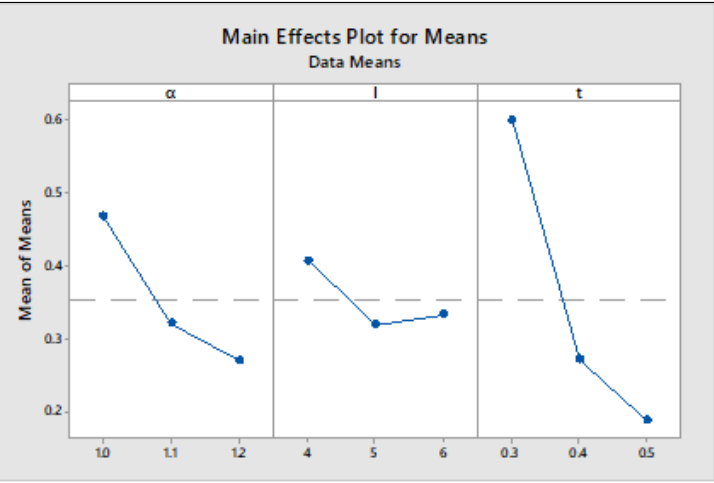

(a)

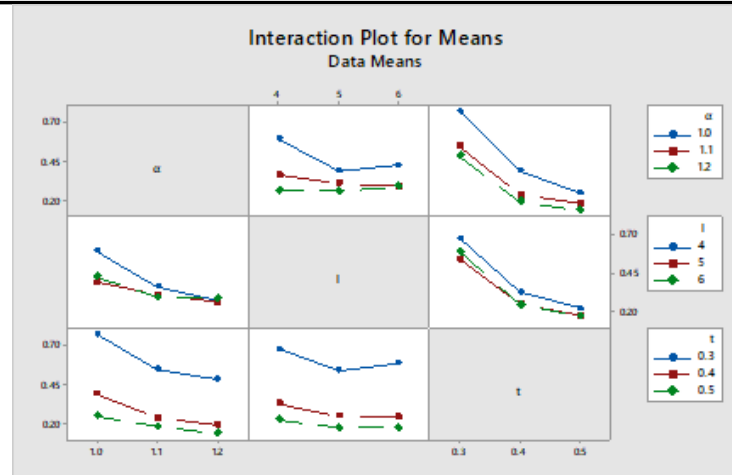

(b)

Figure 7. Main effects and interaction plot for mean for GTs-TOPSIS

Table 12. Analysis of variance (ANOVA) result.

\begin{tabular}{|c|c|c|c|c|c|c|c|}
\hline Source & DF & Seq SS & Contribution & Adj SS & Adj MS & F-Value & P-Value \\
\hline$\alpha$ & 2 & 0.18796 & $15.66 \%$ & 0.187959 & 0.093979 & 18.07 & 0.001 \\
\hline 1 & 2 & 0.04044 & $3.37 \%$ & 0.040437 & 0.020218 & 3.89 & 0.066 \\
\hline $\mathrm{t}$ & 2 & 0.85409 & $71.18 \%$ & 0.854093 & 0.427047 & 82.1 & 0 \\
\hline$\alpha * 1$ & 4 & 0.04096 & $3.41 \%$ & 0.040961 & 0.01024 & 1.97 & 0.192 \\
\hline$\alpha * \mathrm{t}$ & 4 & 0.02885 & $2.40 \%$ & 0.028846 & 0.007212 & 1.39 & 0.321 \\
\hline $1 * \mathrm{t}$ & 4 & 0.00601 & $0.50 \%$ & 0.006005 & 0.001501 & 0.29 & 0.877 \\
\hline Error & 8 & 0.04161 & $3.47 \%$ & 0.041615 & 0.005202 & & \\
\hline Total & 26 & 1.19992 & $100.00 \%$ & & & & \\
\hline $\mathrm{S}$ & $\mathrm{R}-\mathrm{sq}$ & R-sq(adj) & PRESS & R-sq(pred) & & & \\
\hline 0.072124 & $96.53 \%$ & $88.73 \%$ & 0.474017 & $60.50 \%$ & & & \\
\hline
\end{tabular}

Analysis of Variance (ANOVA) output of the multiple performance characteristics was given in Table 12. As shown in Table 12, the thickness and incline angle of the flexure hinge were remarkable factors. The thickness of the flexure hinge had the biggest contribution is $71.18 \%$. Hence, the length of flexure hinge had the most significant impact on the displacement amplifier based on the preferred configuration output. The contribution of the length and incline angle was $3.37 \%$ and $15.66 \%$, respectively. R squared figured out as $96.53 \%$ indicated that this linear regression model was suitable for $96.53 \%$ of data set.

\section{Experiment and confirmation test}

\subsection{Confirmation simulation test}

A demonstration was conducted to verify the quality of the output response. The forecast optimized value was calculated by below equation (26).

$$
\eta_{\text {predict }}=\eta_{t m}+\sum_{i=1}^{t}\left(\eta_{i}-\eta_{t m}\right)
$$

Where $\eta_{\mathrm{tm}}$ is the average value of whole response, $\eta_{\mathrm{i}}$ is the average value of the response at the best level, and $t$ is the quantity of input parameters. The result of the confirmatory experiment shown as Table 13.

In Table 13, the initial parameters from the design requirements are the incline angle of the flexing hinge 1.2 degrees, the length of the flexing hinge $5 \mathrm{~mm}$, and the thickness of the flexing hinge $0.4 \mathrm{~mm}$. The optimum parameters figure out by GRA and Grey-TOPSIS have the same values as the angle of inclination of the flexing hinge 1 degree, the length of the flexing hinge $4 \mathrm{~mm}$, and the thickness of the flexing hinge of $0.3 \mathrm{~mm}$. However, the analytical results show that the estimated coefficient followed the Grey-TOPSIS method is much more robust compared with using the GRA method. The feedback on the improved displacement amplifier using this recommended method. 
Table 13. Initial, predicted, and compared evaluation test.

\begin{tabular}{|c|c|c|c|c|c|}
\hline & \multicolumn{3}{|c|}{ Initial } & \multicolumn{2}{|c|}{ Optimal Parameter } \\
\hline & \multicolumn{3}{|c|}{ GRA } & \multicolumn{2}{|c|}{ Grey-TOPSIS } \\
\hline & \multicolumn{2}{|c|}{ Prediction } & Test & Prediction & Test \\
\hline Level & $\alpha_{3} l_{2} t_{2}$ & $\alpha_{1} 1_{1} t_{1}$ & $\alpha_{1} 1_{1} t_{1}$ & $\alpha_{1} 1_{1} t_{1}$ & $\alpha_{1} 1_{1} t_{1}$ \\
\hline$\alpha$ & 1.2 & & 1 & & 1 \\
\hline 1 & 5 & & 4 & & 4 \\
\hline $\mathrm{t}$ & 0.4 & & 0.3 & & 0.3 \\
\hline $\mathrm{C}$ & 0.1807 & & & 0.7695 & 0.9521 \\
\hline GRG & 0.4293 & 0.859 & 0.975 & & \\
\hline Improvement & & 0.4297 & 0.5457 & 0.588 & 0.771 \\
\hline
\end{tabular}

\subsection{The prototype of the micro gripper}

The parameter of the sample is taken from the optimal result in the Table 5. The optimal geometry parameter of the model is incline angle of 1 degree, the length of $4 \mathrm{~mm}$, and the thickness of $0.3 \mathrm{~mm}$, respectively. To simplify the fabrication manufacturing process and reduce costs, the sample was fabricated by 3D printer. The material is PLA. The prototyping model is shown in Figure 8.

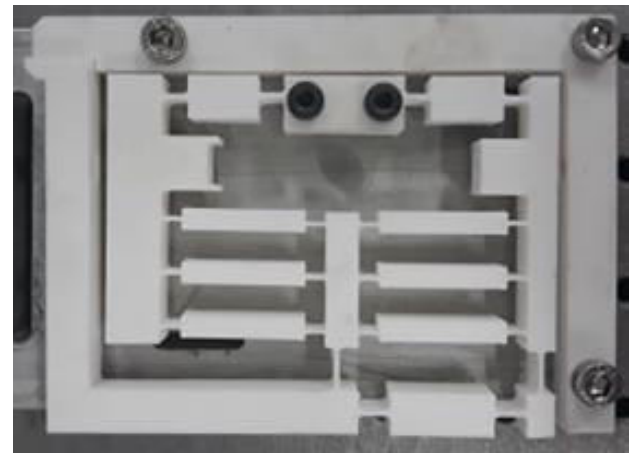

Figure 8. Asymmetric micro-gripper mechanism.

\subsection{Experiment and measuring process}

To verify the performance of the asymmetric microgripper mechanism, it is necessary to perform tests on the micro-clamp device. The devices applied to the experiment are listed as below Table 14. The experiment system consists mainly of a controlled power source, PZT servo controller, analog amplifier, a piezoelectric actuator, a laser measuring device, and an asymmetric micro-gripper mechanism. It is illustrated in Figure 9.

Table 14. Experiment devices list

\begin{tabular}{|c|c|}
\hline A & DPO 2014B digital Oscilloscope \\
\hline B & Analog amplifier SVR 150/3 \\
\hline C & PST controller PI \\
\hline D & DC power supply GP C-60300 \\
\hline E & Laser head LB12(W) \\
\hline F & Laser amplifier reader LB-72(W) \\
\hline G & Probe sensor \\
\hline H & PST 150 \\
\hline
\end{tabular}

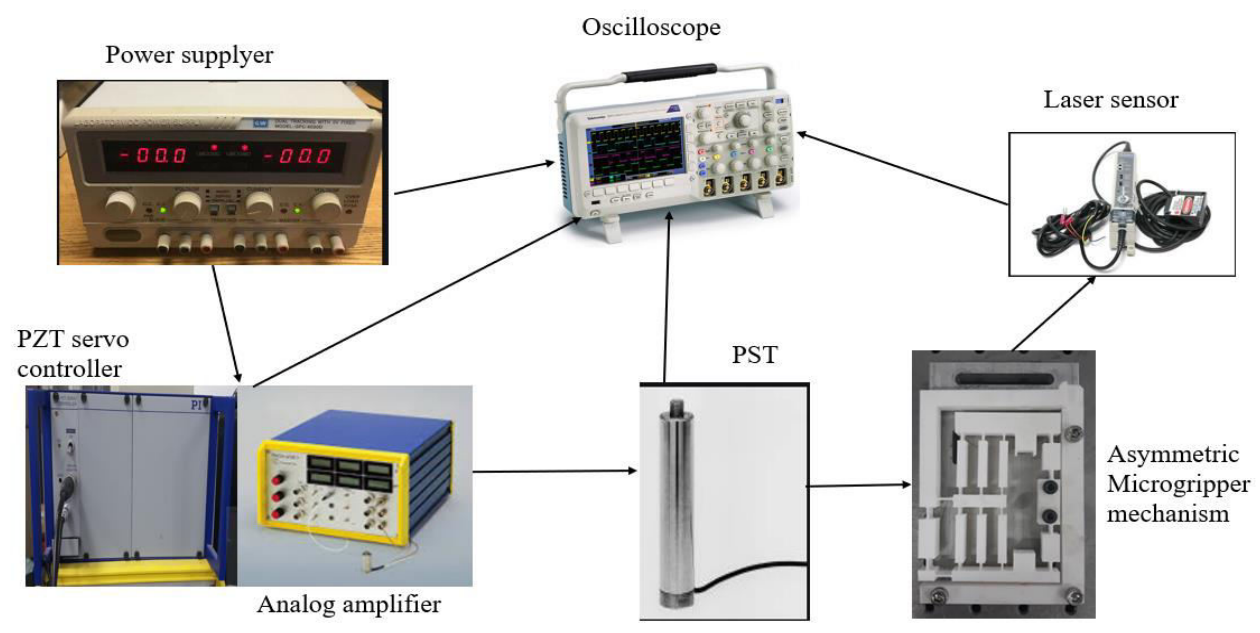

(a) Principle diagram connection 


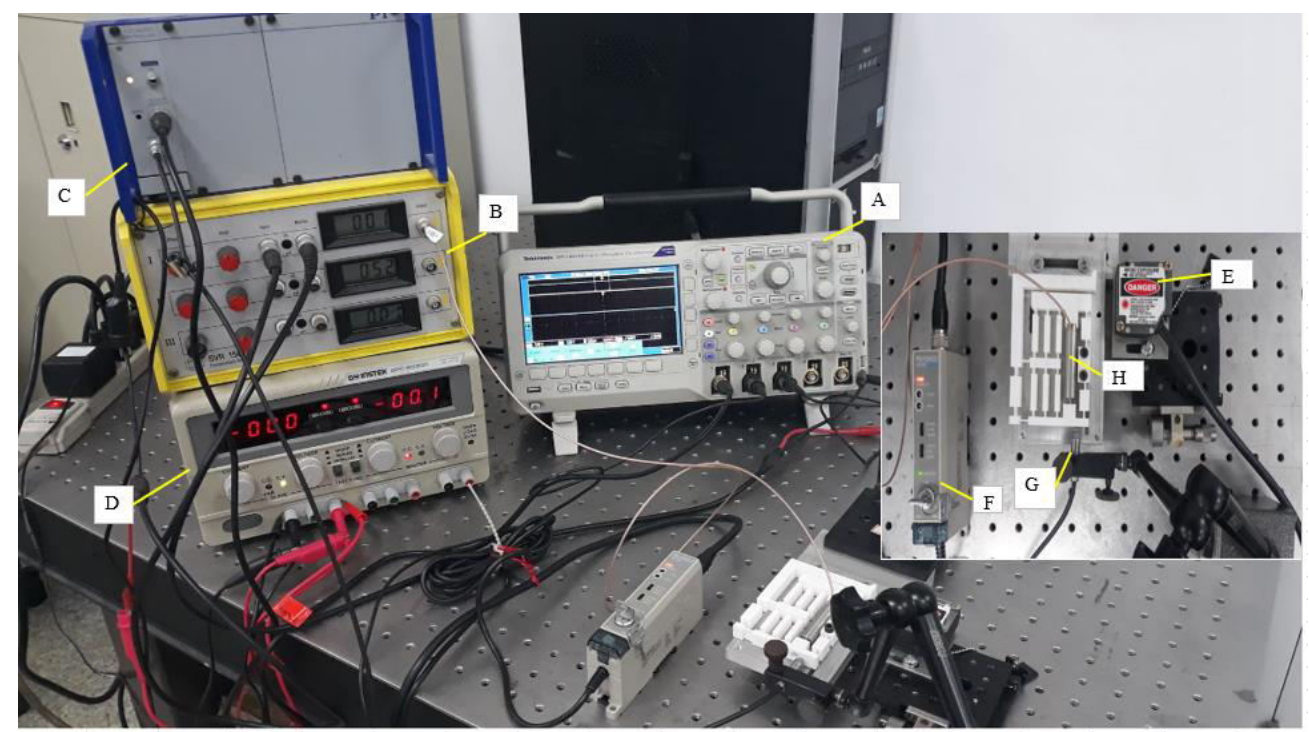

(b) Experiment setup

Figure 9. Experimental layout diagram of the microgripper mechanism.

The value of measuring comparison is taken from the mean of the three measurements. The input displacement of the structure is changed from 0 to $40 \mu \mathrm{m}$ corresponding to $0 \mathrm{~V}$ to $150 \mathrm{~V}$ of the output amplifier controller. The input voltage control of the amplifier is from $0 \mathrm{~V}$ to $5 \mathrm{~V}$. In this case, we observed 10 points with the input displacement from $4 \mu \mathrm{m}$ to $40 \mu \mathrm{m}$ with the pitch is 4 . The resolution of the laser sensor is $0.4 \mathrm{~V} / \mathrm{mm}$. Therefore, we can calculate the displacement output of the micro gripper. The measure result is shown in Table 15 .

In this Table 14, based on the resolution of equipment, we can obtain the displacement output corresponding to the displacement input. The value of the output displacement base on the experiment was compared with the simulation value. The result shown in the ratio amplifier of the structure of micro gripper is approximately 58.4 times. The initial instability of the measurement signal is $0-6 \mu \mathrm{V}$. The maximum error of the signal measurement is $101 \mu \mathrm{m} / 2000 \mu \mathrm{m}$ compared to simulation result. The error is $4.8 \%$. This result is acceptable. The comparison of results is shown in Figure 10.

Table 15. The result of measurement and analysis

\begin{tabular}{|c|c|c|c|c|c|c|c|c|c|}
\hline No & $\begin{array}{l}\text { Output } \\
\text { voltage(V) }\end{array}$ & $\begin{array}{c}\text { Displacement } \\
\operatorname{PST}(\mu \mathrm{m})\end{array}$ & \multicolumn{3}{|c|}{$\begin{array}{c}\text { Mean value of Laser signal } \\
\text { measurement }(\mathrm{mV})\end{array}$} & $\begin{array}{l}\text { Mean } \\
(\mathrm{mV})\end{array}$ & $\begin{array}{c}\text { Displacement } \\
\text { output }\end{array}$ & $\begin{array}{c}\text { Displacement } \\
\text { output }\end{array}$ & $\begin{array}{l}\text { Error } \\
(\%)\end{array}$ \\
\hline 1 & 15 & 4 & 91.31 & 93.7 & 92.52 & 92.5 & 231.2 & 232.7 & 0.7 \\
\hline 2 & 22.5 & 8 & 181.53 & 186.29 & 183.94 & 183.9 & 459.68 & 467.2 & 1.6 \\
\hline 3 & 30 & 12 & 274.92 & 282.11 & 278.56 & 278.5 & 696.32 & 699.9 & 0.5 \\
\hline 4 & 45 & 16 & 367.31 & 376.93 & 372.18 & 372.1 & 930.24 & 929.1 & 0.1 \\
\hline 5 & 60 & 20 & 456.45 & 468.40 & 462.50 & 462.4 & 1156 & 1168.8 & 1.1 \\
\hline 6 & 75 & 24 & 544.50 & 558.76 & 551.72 & 551.6 & 1379.04 & 1401.5 & 1.6 \\
\hline 7 & 90 & 28 & 615.38 & 631.49 & 623.53 & 623.4 & 1558.56 & 1636.0 & 4.7 \\
\hline 8 & 105 & 32 & 721.69 & 740.58 & 731.26 & 731.1 & 1827.84 & 1870.4 & 2.3 \\
\hline 9 & 120 & 36 & 790.50 & 811.19 & 800.97 & 800.8 & 2001.92 & 2103.2 & 4.8 \\
\hline 10 & 150 & 40 & 880.72 & 903.77 & 892.39 & 892.2 & 2230.4 & 2337.6 & 4.6 \\
\hline
\end{tabular}




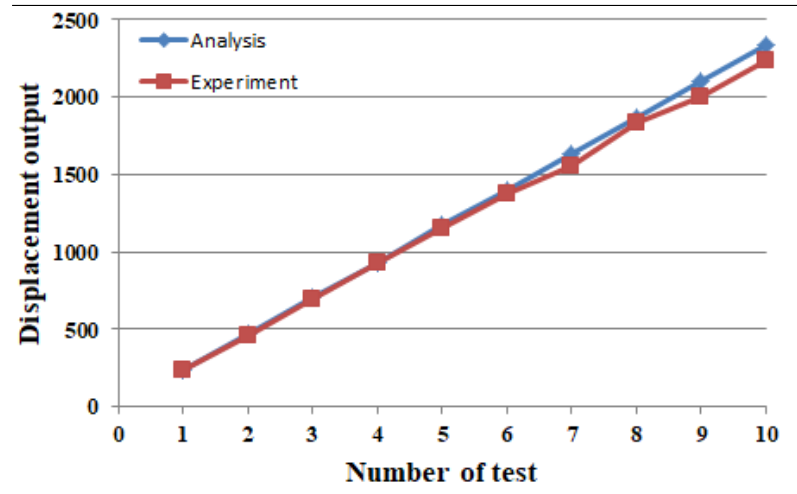

Figure 10. The comparison of the simulation value and experiment value of displacement output.

\section{Conclusions}

The purpose of this study is to achieve a maximum output displacement amplifier ratio by optimizing the dimension of model. Design parameters of a triple-stair bridge-type amplifier structure. The FEA values are integrated with the Grey-TOPSIS method to figure out the best dimension configuration to achieve the maximum output displacement ratio. The results obtained the highest output displacement ratio with the following design parameters: incline angle $(\alpha)$ is 1 degree, length (1) is $4 \mathrm{~mm}$, thickness (t) is $0.3 \mathrm{~mm}$. The input displacement ratio is $0.01 \mathrm{~mm}$, the largest output displacement result is $0.5818 \mathrm{~mm}$, the amplification ratio is 58 times, and the stress after the analysis is $2.432 \mathrm{MPa}$.

In future work, the kinetic analysis can be used to describe and analyze in-depth the performance of the of the flexure hinge with different geometrical parameters on the microgripper mechanism. Further investigation of stiffness and natural frequency analysis of the microgripper mechanism can be conducted. Apply the model to the assembly process of micro components.

\section{Data availability}

All data that support the findings of this study are available from the corresponding author upon reasonable request.

\section{Code availability}

Not applicable

\section{References}

1. Zhong, Y., Shirinzadeh, B., Alici, G., \& Smith, J. (2006). Soft tissue modelling through autowaves for surgery simulation. Medical and Biological Engineering and Computing, 44(9), 805. doi:10.1007/s11517-006-0084-7

2. Zimmermann, S., Tiemerding, T., \& Fatikow, S. (2015). Automated Robotic Manipulation of Individual Colloidal
Particles Using Vision-Based Control. IEEE/ASME

Transactions on Mechatronics, 20(5), 2031-2038.

doi: 10.1109/TMECH.2014.2361271

3. Carrozza, M. C., Eisinberg, A., Menciassi, A., Campolo, D., Micera, S., \& Dario, P. (2000). Towards a force-controlled microgripper for assembling biomedical microdevices. Journal of Micromechanics and Microengineering, 10(2), 271276.

doi: 10.1088/0960-1317/10/2/328

4. Rakotondrabe, M., \& Ivan, I. A. (2011). Development and Force/Position Control of a New Hybrid Thermo-Piezoelectric Micro Gripper Dedicated to Micromanipulation Tasks. IEEE Transactions on Automation Science and Engineering, 8(4), 824-834.

doi: 10.1109/TASE.2011.2157683

5. Gu, G., Zhu, L., Su, C., Ding, H., \& Fatikow, S. (2015). Proxy-Based Sliding-Mode Tracking Control of PiezoelectricActuated Nanopositioning Stages. IEEE/ASME Transactions on Mechatronics, 20(4), 1956-1965.

doi: 10.1109/TMECH.2014.2360416

6. Qin, Y., Shirinzadeh, B., Tian, Y., \& Zhang, D. (2013). Design issues in a decoupled XY stage: Static and dynamics modeling, hysteresis compensation, and tracking control. Sensors and Actuators A: Physical, 194, 95-105.

doi: https://doi.org/10.1016/j.sna.2013.02.003

7. Tian, Y., Shirinzadeh, B., \& Zhang, D. (2009). A flexurebased mechanism and control methodology for ultra-precision turning operation. Precision Engineering, 33(2), 160-166. doi: https://doi.org/10.1016/j.precisioneng.2008.05.001

8. Somà, A., Iamoni, S., Voicu, R., Müller, R., Al-Zandi, M., \& Wang, C. (2018). Design and experimental testing of an electro-thermal microgripper for cell manipulation. Microsystem Technologies, 24(2), 1053-1060.

doi: 10.1007/s00542-017-3460-3

9. Murugu Nachippan, N., Venkatesh, A. P., \& Muniyappan, M. (2018). Modelling and Analysis of Piezoelectric Microgripper for Unmanned Aerial Vehicle. Materials Today: Proceedings, 5(9, Part 3), 19456-19462.

doi: https://doi.org/10.1016/j.matpr.2018.06.306

10. Haddab, Y., Chaillet, N., \& Bourjault, A. (2000, 31 Oct.-5 Nov. 2000). A microgripper using smart piezoelectric actuators. Paper presented at the Proceedings. 2000 IEEE/RSJ International Conference on Intelligent Robots and Systems (IROS 2000) (Cat. No.00CH37113). doi: $10.1109 /$ IROS.2000.894679

11. Long, Z., Zhang, J., Liu, Y., Han, C., Li, Y., \& Li, Z. (2017). Dynamics Modeling and Residual Vibration Control of a Piezoelectric Gripper During Wire Bonding. IEEE Transactions on Components, Packaging and Manufacturing Technology, 7(12), 2045-2056.

doi: 10.1109/TCPMT.2017.2723458

12. Sreekumar, M., Nagarajan, T., Singaperumal, M., Zoppi, M., \& Molfino, R. (2007). Critical review of current trends in shape memory alloy actuators for intelligent robots. Industrial Robot: An International Journal, 34, 285-294.

doi: 10.1108/01439910710749609

13. Nonaka, K., Sakai, K., \& Baillieul, J. (2004, 4-6 Aug. 2004). Open loop oscillatory control for electromagnetic actuated microgrippers. Paper presented at the SICE 2004 Annual Conference. ISBN:4-907764-22-7

14. Despa, V., Catangiu, A., Ivan, I., Gurgu, V., \& Ardeleanu, M. (2014). MODELING AND CONTROL OF A MICROGRIPPER BASED ON ELECTROMAGNETIC ACTUATION. Paper presented at the The Scientific Bulletin of VALAHIA University - MATERIALS and MECHANICS.

15. Alneamy, A., Khater, M., Abdel-Aziz, A., Heppler, G., \& Abdel-Rahman, E. (2020). Electrostatic arch micro-tweezers. International Journal of Non-Linear Mechanics, 118, 103298. doi: https://doi.org/10.1016/j.ijnonlinmec.2019.103298 
16. Chen, W., Zhang, X., \& Fatikow, S. (2016). A novel microgripper hybrid driven by a piezoelectric stack actuator and piezoelectric cantilever actuators. Rev Sci Instrum, 87(11), 115003.

doi: https://doi.org/10.1063/1.4967218

17. Shi, B., Wang, F., Huo, Z., Tian, Y., Zhao, X., \& Zhang, D. (2018, 13-17 Aug. 2018). Design and Characteristics of a Novel Compliant Symmetric Microgripper Mechanism. Paper presented at the 2018 IEEE International Conference on Manipulation, Manufacturing and Measurement on the Nanoscale (3M-NANO).

doi: 10.1109/3M-NANO.2018.8552246

18. Jain, R., Majumder, S., Ghosh, B., \& Saha, S. (2015). Design and manufacturing of mobile micro manipulation system with a compliant piezoelectric actuator based micro gripper. Journal of Manufacturing Systems, 35.

doi: 10.1016/j.jmsy.2014.12.001

19. Liaw, H. C., Shirinzadeh, B., \& Smith, J. (2008). SlidingMode Enhanced Adaptive Motion Tracking Control of Piezoelectric Actuation Systems for Micro/Nano Manipulation. IEEE Transactions on Control Systems Technology, 16(4), 826-833. doi: 10.1109/TCST.2007.916301

20. Long, Z., Zhang, J., Liu, Y., Han, C., Li, Y., \& Li, Z. (2017). Dynamics Modeling and Residual Vibration Control of a Piezoelectric Gripper During Wire Bonding. IEEE Transactions on Components, Packaging and Manufacturing Technology, 7(12), 2045-2056. doi: 10.1109/TCPMT.2017.2723458

21. Zubir, M., Shirinzadeh, B., \& Tian, Y. (2009). Development of a novel flexure-based microgripper for high precision micro-object manipulation. Sensors and Actuators A: Physical, 150(2), 257-266. doi: https://doi.org/10.1016/j.sna.2009.01.016

22. Rakotondrabe, M., \& Ivan, I. A. (2011). Development and Force/Position Control of a New Hybrid Thermo-Piezoelectric MicroGripper Dedicated to Micromanipulation Tasks. IEEE Transactions on Automation Science and Engineering, 8(4), 824-834. doi: 10.1109/TASE.2011.2157683

23. Yang, S., \& Xu, Q. (2017). A review on actuation and sensing techniques for MEMS-based microgrippers. Journal of MicroBio Robotics, 13(1), 1-14. doi: 10.1007/s12213-017-0098-2

24. Wu, Z., \& Xu, Q. (2018). Survey on Recent Designs of Compliant Micro-/Nano-Positioning Stages. Actuators, 7. doi: 10.3390/act7010005

25. Das, T. K., Shirinzadeh, B., Ghafarian, M., Al-Jodah, A., Zhong, Y., \& Smith, J. (2020). Design, analysis and experimental investigations of a high precision flexure-based microgripper for micro/nano manipulation. Mechatronics, 69, 102396. doi: https://doi.org/10.1016/j.mechatronics.2020.102396

26. Bao, L. and X. Zhou, Design of micro-gripper with two-stage amplifier for micro-assembly and its experimental research. Machine Design and Research, 2014. 30(1): p. 47-50. doi: 10.13952/j.cnki.jofmdr.2014.01.012

27. Chen, G., Ma, Y., \& Li, J. (2016). A tensural displacement amplifier employing elliptic-arc flexure hinges. Sensors and Actuators A: Physical, 247, 307-315. doi: https://doi.org/10.1016/j.sna.2016.05.015

28. Chen, X., Deng, Z., Hu, S., Gao, J., \& Gao, X. (2019). Design of a flexible piezoelectric microgripper based on combined amplification principles. Nanotechnology and Precision Engineering, 2(3), 138-143. doi: https://doi.org/10.1016/j.npe.2019.10.006

29. Sun, X., Chen, W., Fatikow, S., Tian, Y., Zhou, R., Zhang, J., \& Mikczinski, M. (2015). A novel piezo-driven microgripper with a large jaw displacement. Microsystem Technologies,
21(4), 931-942.

doi: 10.1007/s00542-014-2199-3

30. Wang, F., Liang, C., Tian, Y., Zhao, X., \& Zhang, D. (2016). Design and Control of a Compliant Microgripper With a Large Amplification Ratio for High-Speed Micro Manipulation. IEEE/ASME Transactions on Mechatronics, 21(3), 1262-1271. doi: 10.1109/TMECH.2016.2523564

31. Koo, B., Hong, S., Kim, S., Kang, C., Han, S., Oh, K., \& Kim, Y. (2015). Design and Application of a Novel In Situ NanoManipulation Stage for Transmission Electron Microscopy. Microscopy and Microanalysis, 21, 1-9. doi: $10.1017 / \mathrm{S} 1431927615000239$

32. Xing, Q. (2015). Design of asymmetric flexible micro-gripper mechanism based on flexure hinges. Advances in Mechanical Engineering, 7(6), 1687814015590331. doi: $10.1177 / 1687814015590331$

33. Chen, W., Zhang, X., Li, H., Wei, J., \& Fatikow, S. (2017). Nonlinear analysis and optimal design of a novel piezoelectric-driven compliant microgripper. Mechanism and Machine Theory, 118, 32-52. doi: https://doi.org/10.1016/j.mechmachtheory.2017.07.011

34. Ho, N., Dao, T., Chau, N., \& Huang, S. (2019). Multiobjective optimization design of a compliant microgripper based on hybrid teaching learning-based optimization algorithm. Microsystem Technologies, 25. doi: 10.1007/s00542-018-4222-6

35. Xiao, S., Li, Y., \& Zhao, X. (2011, 17-19 Sept. 2011). Optimal design of a novel micro-gripper with completely parallel movement of gripping arms. Paper presented at the 2011 IEEE 5th International Conference on Robotics, Automation and Mechatronics (RAM). doi: 10.1109/RAMECH.2011.6070452

36. Verotti, M., Di Giamberardino, P., Belfiore, N. P., \& Giannini, O. (2019). A genetic algorithm-based method for the mechanical characterization of biosamples using a MEMS microgripper: numerical simulations. Journal of the Mechanical Behavior of Biomedical Materials, 96, 88-95. doi: https://doi.org/10.1016/j.jmbbm.2019.04.023

37. Gok, A. (2015). A new approach to minimization of the surface roughness and cutting force via fuzzy TOPSIS, multiobjective grey design and RSA. Measurement, 70, 100-109. doi: https://doi.org/10.1016/j.measurement.2015.03.037

38. Tiwary, A. P., Pradhan, B. B., \& Bhattacharyya, B. (2014). Application of multi-criteria decision making methods for selection of micro-EDM process parameters. Advances in Manufacturing, 2(3), 251-258. doi: 10.1007/s40436-013-0050-1

39. Wang, C., Tu, S., Chen, M., \& Yuan, Y. (2016). Optimal Selection of a Longwall Mining Method for a Thin Coal Seam Working Face. Arabian Journal for Science and Engineering, 41(9), 3771-3781. doi: $10.1007 / \mathrm{s} 13369-016-2260-\mathrm{x}$

40. Roy, M. K., Ray, A., \& Pradhan, B. B. (2014). Non-traditional machining process selection using integrated fuzzy AHP and QFD techniques: a customer perspective. Production \& Manufacturing Research, 2(1), 530-549. doi: 10.1080/21693277.2014.938276

41. Arun, P., \& Avanish, D. (2013). Modeling and optimization of kerf taper and surface roughness in laser cutting of titanium alloy sheet. Journal of Mechanical Science and Technology, 27. doi: 10.1007/s12206-013-0527-7

42. Şengül, Eren, Shiraz, E., Gezder, \& Şengül. (2015). Fuzzy TOPSIS method for ranking renewable energy supply systems in Turkey. Renewable Energy, 75, 617-625. doi: https://doi.org/10.1016/j.renene.2014.10.045

43. Liu, S., Forrest, J., \& Yang, Y. (2011, 15-18 Sept. 2011). A brief introduction to grey systems theory. Paper presented at 
the Proceedings of 2011 IEEE International Conference on Grey Systems and Intelligent Services. doi: 10.1109/GSIS.2011.6044018

44. Morán, J., Granada, E., Míguez, J. L., \& Porteiro, J. (2006). Use of grey relational analysis to assess and optimize small biomass boilers. Fuel Processing Technology, 87, 123-127. doi: 10.1016/j.fuproc.2005.08.008

45. Olson, D., \& Wu, D. (2006). Simulation of Fuzzy Multiattribute Models for Grey Relationships. European Journal of Operational Research, 175, 111-120. doi: 10.1016/j.ejor.2005.05.002

46. Wen, K., Chang, T., \& You, M. (1998, 14-14 Oct. 1998). The grey entropy and its application in weighting analysis. Paper presented at the SMC'98 Conference Proceedings. 1998 IEEE International Conference on Systems, Man, and Cybernetics (Cat. No.98CH36218). ISBN: 0-7803-4778-1

47. Lai, YJ., Liu, TY., \& Hwang, CL. (1994). TOPSIS for MODM. European Journal of Operational Research, 76(3), 486-500.

doi: https://doi.org/10.1016/0377-2217(94)90282-8

48. Hwang CL., Yoon K. (1981) Methods for Multiple Attribute Decision Making. In: Multiple Attribute Decision Making. Lecture Notes in Economics and Mathematical Systems, vol 186. Springer, Berlin, Heidelberg.

doi: https://doi.org/10.1007/978-3-642-48318-9_3

49. Zhang, K., Zhan, J., \& Yao, Y. (2019). TOPSIS method based on a fuzzy covering approximation space: An application to biological nano-materials selection. Information Sciences, 502, 297-329.

doi: 10.1016/j.ins.2019.06.043

50. Vahdani, B., Mousavi, S. M., \& Tavakkoli-Moghaddam, R. (2011). Group decision making based on novel fuzzy modified TOPSIS method. Applied Mathematical Modelling, 35(9), 4257-4269.

doi: https://doi.org/10.1016/j.apm.2011.02.040

\section{Funding}

All authors declare that no funds, grants, or other support were received during the preparation of this manuscript.

\section{Ethics declarations}

\section{Conflict of interest}

All authors declare no competing interests.

\section{Ethics approval}

Not applicable.

Content to participate

Not applicable.

Content to publication

Not applicable. 